\title{
Analysis of caspase activities in rat mammary tumours induced by $N$-methyl-nitrosourea
}

\author{
M.A. PUERTOLLANO ${ }^{1 *}$, M.P.CARRERA ${ }^{2 *}$, E. PUERTOLLANO ${ }^{1}$, G. ÁLVAREZ DE CIENFUEGOS ${ }^{1}$, \\ M.J. RAMíREZ-EXPÓSITO ${ }^{3}$, M.A. DE PABLO ${ }^{1}$ and J.M. MARTíNEZ-MARTOS ${ }^{3}$ \\ ${ }^{1}$ Unit of Microbiology, Department of Health Sciences, Faculty of Experimental Sciences, University of Jaén, \\ E-23071 Jaén; ${ }^{2}$ Unit of Cellular Physiology, Institute of Bioengineering, University Miguel Hernández, Elche; ${ }^{3}$ Unit of \\ Physiology, Department of Health Sciences, Faculty of Experimental Sciences, University of Jaén, E-23071 Jaén, Spain
}

Received February 14, 2008; Accepted May 23, 2008

DOI: 10.3892/or_00000056

\begin{abstract}
Normal breast development is controlled by a balance between cell proliferation and apoptosis. The balance between the two parameters is crucial for determining the growth or regression of breast tumours in response to therapies and treatments. Therefore, it is necessary to understand the role of apoptosis in tumour progression. Active caspases participate as essential elements in the execution of apoptotic mechanisms. In the present study, we analysed the activities of caspase-3, -8 and -9 as well as cytochrome $c$ release in $\mathrm{N}$-methyl-nitrosourea (NMU)-induced rat mammary tumours, in order to establish the apoptotic events that occur in tumour growth in this animal model. Forty female virgin Wistar rats were randomly divided into two groups. One group was injected intraperitoneally with three doses of $50 \mathrm{mg} / \mathrm{kg}$ body weight of NMU. The control group received the vehicle only. After 122 days of NMU injection, the rats were sacrificed and the tumours were excised and processed. Results showed that in mammary tumours induced by NMU, the apoptotic death receptor-mediated pathway is activated through caspase- 3 and -8 , but the apoptotic mitochondrial pathway is suppressed through a non-activating process of caspase- 9 activity, despite the release of cytochrome $c$. In conclusion, these findings have demonstrated a suppression of the apoptotic mitochondrial pathway through a non-activating process of caspase-9 activity, despite the release of cytochrome $c$ in mammary tumours induced by NMU. Although the apoptotic death
\end{abstract}

Correspondence to: Dr José Manuel Martínez-Martos, Department of Health Sciences, Unit of Physiology, Faculty of Experimental and Health Sciences, University of Jaén, Campus Universitario Las Lagunillas, E-23071 Jaén, Spain

E-mail: jmmartos@ujaen.es

${ }^{*}$ Contributed equally

Key words: caspase 3, caspase 6, caspase 9, cytochrome $c$, apoptosis, breast cancer, $\mathrm{N}$-methyl-nitrosourea, rat mammary tumours receptor-mediated pathway is activated, it is not enough to maintain the balance between proliferation and apoptosis, and thus determine the overall growth of the tumour.

\section{Introduction}

Animal models of breast cancer constitute a useful tool for dissecting the several processes of carcinogenesis. In the $N$ methyl-nitrosourea (NMU)-induced rat model, mammary tumours are estrogen-dependent, aggressive and locally invasive, in a similar degree to that observed in the human disease (1-8). Breast cancer is the most common malignancy in women, and comprises $18 \%$ of all cancers in women (9-11). The poor survival rates from breast cancer have decreased by $>25 \%$ due to the improved use of adjuvant tamoxifen and chemotherapy. Therefore, current research is focused on a greater understanding of the response and resistance to treatment, including the role of apoptosis (12-14).

Normal breast development is controlled by a balance between cell proliferation and apoptosis. The balance between the two parameters is crucial in determining the overall growth or regression of the tumour (15-17) in response to therapies and treatments. Therefore, it is necessary to better understand the role of apoptosis in tumour progression.

Active caspases participate as essential elements in the execution of apoptotic mechanisms (18). Caspases have widely been defined as intracellular cysteine-containing proteases that cleave different cytoplasmic, structural and nuclear proteins after an aspartate residue (19). Caspases are synthesized as inactive zymogens, which become proteolytically cleaved during apoptosis to generate active enzymes. Thus, caspase activation can be initiated by two different pathways: one mediated by a cell surface receptor (exogenous pathway), and the other executed by the release of mitochondrial factors (endogenous pathway). Caspase-8 acts as the most upstream caspase in apoptotic signaling initiated by Fas (CD95), tumour necrosis factor (TNF) receptor (TNFR), and TNFRrelated death receptors including TRAIL (TNF-related apoptosis-inducing ligand) receptors (TRAIL-R1 and -R2) and death receptors (DRs; e.g., DR3) (20-22). Two pathways of the Fas death receptor have been defined depending on the participation of cytochrome $c(23,24)$. The first involves the 
direct activation of caspase- 3 by caspase- 8 without the contribution of cytochrome $c$ release. The second involves the release of this mitochondrial factor by caspase- 8 via Bid. Physical or chemical factors may be involved in the initiation of apoptosis through the mitochondrial release of cytochrome $c$ as well as of other products. Cytochrome $c$ binds to the adaptor molecule apoptosis protease-activating factor 1 (Apaf-1), and this complex induces the activation of pro-caspase-9 (25).

The present study analysed the activities of caspase- $3,-8$ and -9 as well as the cytochrome $c$ release in NMU-induced rat mammary tumours, in order to establish the apoptotic events that occur in tumour growth in this animal model.

\section{Materials and methods}

Animals and treatment. Forty female virgin Wistar rats $(164.7 \pm 4.7 \mathrm{~g}$ body weight) were used in this study. The animals were provided from the animal house-care of the University of Jaén, and maintained in an environment controlled under constant temperature $\left(25^{\circ} \mathrm{C}\right)$ with a $12 \mathrm{~h}$ light/12 h-dark cycle. All animals were allowed access to water and food ad libitum. The experimental procedures for animal use and care were in accordance with the European Community Council directive (86/609/EEC). The rats were randomly divided into two groups. One group was injected intraperitoneally with three doses of $50 \mathrm{mg} / \mathrm{kg}$ body weight of NMU dissolved in distilled water $(10 \mathrm{mg} / \mathrm{ml})$ at 50,80 and 110 days after birth. Tumours induced by this method are oestrogen-dependent (26). The rats were in estrus at the first NMU injection, verified by daily vaginal smears. The control group received the vehicle only. For tumour detection and growth control, the rats were examined by palpation 2 days each week after the second NMU injection. The following tumour growth parameters were determined: latency period (LP), as the number of days between the first NMU injection and the appearance of the first tumour, with a value of 113.0 \pm 4.2 days (mean \pm SEM); tumour incidence $(\mathrm{TI})$, as the percentage of the rats that developed at least one tumour, with a value of $60 \%$; and the mean tumour number per rat $(\mathrm{n} / \mathrm{t})$, as the number of tumours per rat in those animals developing at least one tumour, with a value of $1.93 \pm 0.4$ tumours $($ mean \pm SEM $)$.

Tissue sample preparation. After 122 days following the first NMU injection, animals were sacrificed under equithensin anaesthesia ( $2 \mathrm{ml} / \mathrm{kg}$ body weight). Samples from normal breast or mammary tumours were quickly removed and frozen at $-80^{\circ} \mathrm{C}$, until use. The tissue samples were homogenized in 10 volumes of $10 \mathrm{mM} \mathrm{HCl-Tris} \mathrm{buffer}(\mathrm{pH} \mathrm{7.4)}$ and centrifuged for clarification at $10,000 \mathrm{rpm}$ for $10 \mathrm{~min}$ at $4^{\circ} \mathrm{C}$. The resulting supernatants were used to measured enzyme activities and the protein content (see below), and were assayed in triplicate.

Caspase-3 activity assay. Caspase-3 (CPP32/apopain) activity in cell lysates was measured using a fluorometric assay kit (EnzChek Caspase-3 assay kit, Molecular Probes, Eugene, OR, USA), as described in the manufacturer's instructions. Briefly, tissue homogenates were added with $50 \mu$ l of substrate working solution with dithiothreitol (DTT) and $10 \mu \mathrm{l}$ of $5 \mathrm{mM}$ fluorescent substrate Z-DEVD-R110. Fluorescence was measured from cleavage of the substrate Z-DEVD-R110 [bis-(N-CBZ-L-aspartyl-L-glutamyl-L-valyl-L-aspartic acid amide)] in which rhodamine 110 is generated from the ZDEVD-E110 substrate by caspase action. Samples were transferred to individual wells of a 96-well plate and incubated at room temperature for $30 \mathrm{~min}$. Caspase- 3 activity was quantified on a fluorescence spectrophotometer (Varian Cary Eclipse, Mulgrave, Victoria, Australia) at an excitation wavelength of $488 \mathrm{~nm}$ and at an emission wavelength of $530 \mathrm{~nm}$.

Caspase- 8 and -9 activity assay. The activities of caspase- 8 (also known as FLICE) and caspase-9 (also known as ICELAP-6) were examined using colorimetric assay kits according to the manufacturer's instructions (R\&D Systems Inc., USA). The assay is based on the spectrophotometric detection of the chromophore p-nitroanilide (pNA) after cleavage from the labelled substrate that recognizes an optimal tetrapeptide sequence of the individual activation sites. Briefly, tissue homogenates $(200 \mu \mathrm{g}$ of total protein, as determined by the BioRad protein assay, BioRad, Hercules, CA, USA) were incubated with $5 \mu \mathrm{l}$ of the substrates Ac-IETD-pNA (caspase-8) or Ac-LEHD-pNA (caspase-9) in $50 \mu 1$ caspase assay buffer. After incubation at $37^{\circ} \mathrm{C}$ for $2 \mathrm{~h}$, the release of pNA was measured at $405 \mathrm{~nm}$ using a microplate spectrophotometer (BioRad).

Measurement of cytochrome c release. Cytosolic cytochrome $c$ was quantified using an ELISA kit that employs the sandwich enzyme immunoassay technique (Rat/Mouse Cytochrome $c$ Quantikine ELISA Kit, R\&D Systems, Inc.). The assays were performed following the manufacturer's instructions. All assays were measured in triplicate.

Statistical analysis. To analyse the differences between the control group and animals with mammary tumours induced by NMU injections, we used the unpaired Student's t-test. A simple regression analysis was used to analyse the relation between the tumour number and cytochrome $c$. The data and statistics obtained are given in Table I. Caspase- 3 and -8 levels were used to explain the changes of the dependent variable tumour volume ( major diameter $\mathrm{x}$ minor diameter ${ }^{2}$ ). A stepwise regression was carried out to select the best independent variables, following as a criterion the minimum value for Mallows'Cp. Then, with the $9 \mathrm{R}$ program in the BMDP statistical package, the best regression was selected. The data and statistics obtained are given in Tables II-IV. Comparisons with $\mathrm{P}<0.05$ were considered to be statistically significant.

\section{Results}

Caspase activities. In the present study, we measured the enzymatic activity of the effector caspase-3, as well as the enzymatic activities of the two regulatory or initiator caspases -8 and -9 in rat mammary tumours induced by NMU and breast tissue from the control rats (Fig. 1). Caspase-3 and -8 from NMU-treated rats significantly increased $(\mathrm{P}<0.001$ and $\mathrm{P}<0.01$, respectively) when compared with the control group (Fig. 1A and B). However, caspase-9 activity was not modified (Fig. 1C). A multiple regression analysis showed a signifi- 
Table I. Values of experimental and calculated tumour number from the simple regression analysis.

\begin{tabular}{lcrc}
\hline Rat no. & $\begin{array}{c}\text { Tumour no. } \\
\text { (experimental values) }\end{array}$ & $\begin{array}{c}\text { Tumour no. } \\
\text { (calculated values) }\end{array}$ & Variation (\%) \\
\hline 1 & 6 & 4.42 & 35.740 \\
2 & 1 & 2.38 & -57.980 \\
3 & 1 & 2.32 & -56.890 \\
4 & 1 & 0.68 & 47.059 \\
5 & 4 & 1.45 & 175.860 \\
6 & 5 & 5.00 & 0.000 \\
7 & 2 & 1.70 & 17.650 \\
8 & 1 & 2.38 & -57.980 \\
9 & 2 & 2.64 & -24.240 \\
\hline
\end{tabular}

${ }^{\mathrm{a}}$ Variation $(\%)=100 \mathrm{x}$ (tumour number experimental - tumour number calculated)/tumour number calculated.

Table II. Values of experimental and calculated tumour volume $\left(\mathrm{cm}^{3}\right)$ from the multiple regression analysis.

\begin{tabular}{lccr}
\hline Rat no. & $\begin{array}{c}\text { Tumour volume } \\
\text { (experimental values) }\end{array}$ & $\begin{array}{c}\text { Tumour volume } \\
(\text { calculated values) }\end{array}$ & -5.80 \\
\hline 1 & 5.36 & 5.69 & 132.50 \\
2 & 9.37 & 4.03 & -63.23 \\
3 & 0.50 & 1.36 & -3.98 \\
4 & 21.43 & 22.32 & 25.70 \\
5 & 24.50 & 19.49 & -68.27 \\
6 & 2.11 & 6.65 & -37.92 \\
7 & 7.81 & 12.58 & -9.55 \\
9 & 9.37 & 10.36 & 102.02 \\
\hline
\end{tabular}

${ }^{\mathrm{a}}$ Variation $(\%)=100 \mathrm{x}$ (tumour volume experimental - tumour volume calculated)/tumour volume calculated.

Table III. Multiple regression model for tumour volume. ${ }^{\mathrm{a}}$

\begin{tabular}{lrrc}
\hline Variable & $\begin{array}{r}\text { Regression } \\
\text { coefficient }\end{array}$ & $\begin{array}{c}\text { Standard } \\
\text { error }\end{array}$ & $\begin{array}{c}\text { Contribution } \\
\text { to R-SQ }\end{array}$ \\
\hline Constant & 12.894 & 8.14 & - \\
Caspase-3 & 17.028 & 3.67 & 0.6698 \\
Caspase-8 & -3497.010 & 936.00 & 0.4360 \\
\hline
\end{tabular}

${ }^{\mathrm{a}} \mathrm{n}=9$; Mallows' $\mathrm{C} p=3.0$; mean absolute error: 2.75 ; standard error of estimation: $4.157 ; \mathrm{R}=0.9013 ; \mathrm{R}^{2}=0.8125 ; \mathrm{F}(2,6)=13.01$ and $\mathrm{P}=0.0066$

cant relationship between caspase- 3 and -8 activities and tumour volume in this animal model of breast cancer. Multiple regression analysis statistics are given in Tables II-IV. Table II illustrates the observed versus the predicted values for the dependent variable tumour volume. It can be used to detect
Table IV. Correlation matrix for the variables used

\begin{tabular}{lccc}
\hline Constant & 1 & & \\
Caspase-3 & -0.3349 & 1 & \\
Caspase-8 & -0.7302 & -0.3796 & 1 \\
\hline
\end{tabular}

cases in which the variance is not constant. Table III shows the results of fitting a multiple linear regression model to describe the relationship between tumour volume and the two independent variables. The equation of the fitted model is: tumour volume $=17.025 \times$ caspase- $3-3497.01 \times$ caspase- $8+$ 12.894. Since the P-value in the ANOVA table is $<0.01$, there is a statistically significant relationship between the variables at the $99 \%$ confidence level. The $\mathrm{R}^{2}$ statistic indicates that this model explains $81.25 \%$ of the variability in tumour volume. The mean absolute error of 2.75 is the average value of the residuals. Table IV shows estimated correlations between the coefficients in the fitted model. These correlations 
A
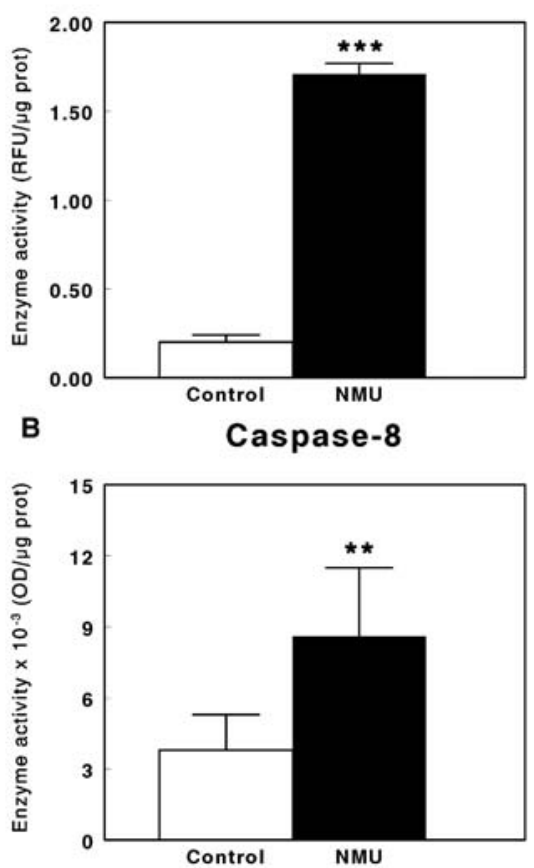

C

Caspase-9

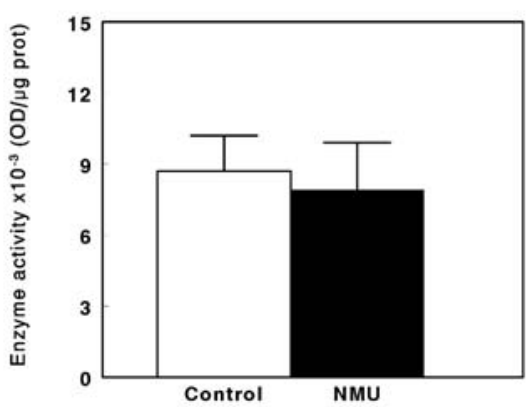

Figure 1. Determination of caspase- $3,-8$ and -9 activities in rat mammary tumours. Caspase-3 activity was assessed by using a fluorometric assay that measures the cleavage of the substrate Z-DEVD-R110 as described in Materials and methods (A). Caspase-8 (B) and -9 (C) were evaluated with a colorimetric assay based on the spectrophotometric detection of the chromophore p-nitroanilide (pNA). The data are expressed in relative units of the fluorescence $(\mathrm{RFU}) / \mu \mathrm{g}$ protein for caspase-3 determination and the optical density (OD) $/ \mu \mathrm{g}$ protein for caspase- 8 and -9 determinations. Each experimental or control treatment was performed in triplicate (mean $\pm \mathrm{SEM}$; $\left.{ }^{* *} \mathrm{P}<0.01 ;{ }^{* * *} \mathrm{P}<0.001\right)$

can be used to detect the presence of serious multicollinearity, i.e., correlation amongst the predictor variables. Fig. 2 shows the component effects of caspase- 3 (Fig. 2A) and caspase- 8 (Fig. 2B) on tumour volume, according to the proposed model. Fig. 3A shows the relationship between the experimental and expected values obtained using the regression equation. This plot allows for the detection of cases in which the variance is not constant. Fig. 3B shows the graph between the residuals versus the experimental tumour volume values. This plot helps to identify sequential correlations among the residuals.

Finally, the activity of caspase-9 is statistically related neither to the number nor the size of mammary tumours induced by NMU in this animal model.
A

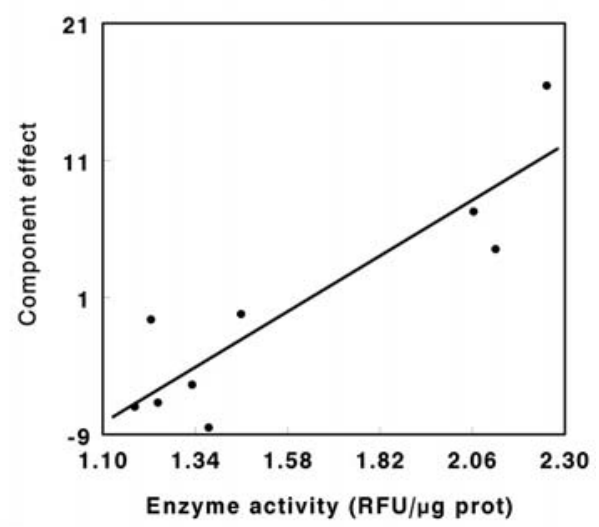

B

Caspase-8

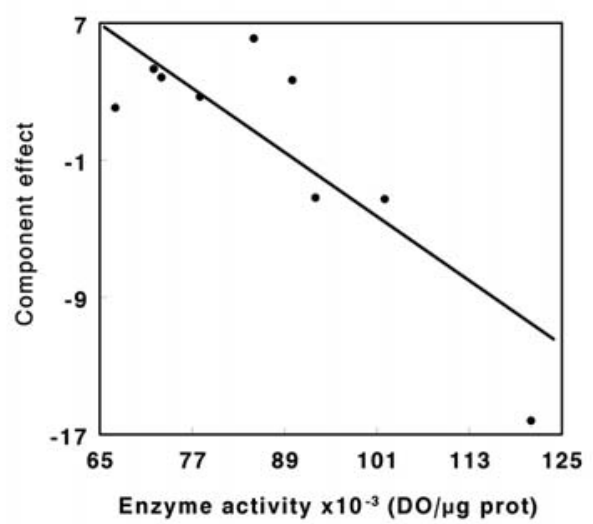

Figure 2. Component effects of (A) caspase-3 and (B) -8 on tumour volume in the multiple regression model proposed.

Cytochrome c release. Normally, the released cytochrome $c$ binds Apaf-1, activates caspase- 9 , which activates caspase- 3 . In our laboratory, cytochrome $c$ released from mitochondria was significantly increased $(\mathrm{P}<0.05)$ in NMU-induced mammary tumours when compared with the control group (Fig. 4). Furthermore, the simple regression analysis demonstrates a significant $(\mathrm{P}<0.05)$ negative relationship between the cytochrome $c$ release and tumour number $(\mathrm{R}=-0.705)$ (Fig. 5).

\section{Discussion}

Programmed cell death represents an essential strategy for the regulation of the dynamic balance in living systems. Normal breast development is regulated by the equilibrium between cell proliferation and apoptosis. Evidence from numerous investigations has demonstrated that tumour growth is not only a consequence of uncontrolled proliferation of cells, but also the result of a reduced or inhibited apoptosis (16). In the present study, we analysed the activity of caspase- $3,-8$ and -9 , as well as the release of cytochrome $c$ in mammary tumours induced in rats by NMU. These factors constitute upstream regulatory elements in apoptosis pathways. Our results demonstrate that this animal model of breast cancer is accompanied by increased levels of caspase- 8 and -3 activities, and an increased release of cytochrome $c$. The caspase- 9 
A

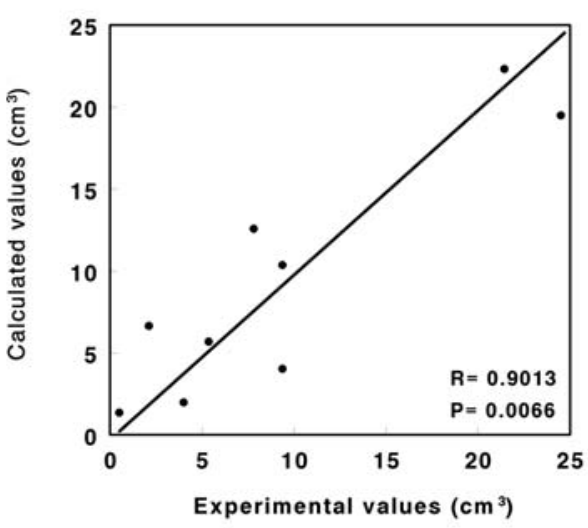

B

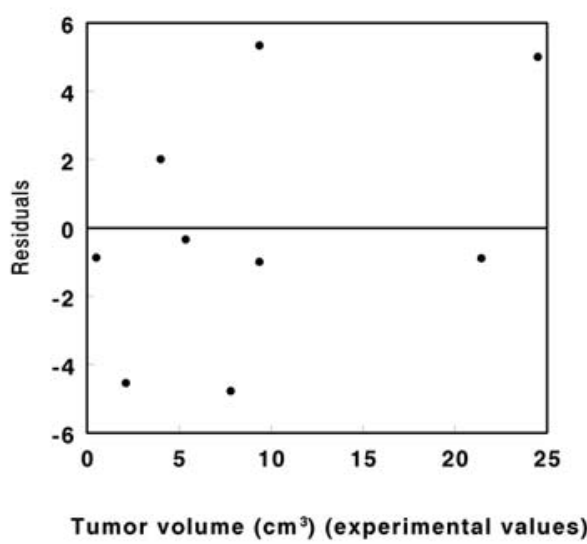

Figure 3. (A) Plot of the experimental vs. expected values of the tumour volume, showing the linear model that describes the relationship between the variables. (B) Plot of residuals vs. experimental values of the tumour volume, showing that the model adequately describes the observed data.

activity, however, was surprisingly not modified. These results agree with those obtained in human breast cancer, where caspases-3, -6 and -8 are associated with higher levels of apoptosis and histological grade (27).

Caspase-3 (an effector caspase) and caspase-8 and -9 (initiator caspases) play key roles in apoptosis. Normally, initiator caspases, once triggered, will activate the downstream effector caspases in a cascade-like pattern (28). The effector caspases will then cleave their substrates, such as poly(ADPribose) polymerase (PARP), and the cleavage of the proteins results ultimately in cellular, morphological and biochemical alterations characteristic of apoptosis (29).

In addition, early investigations reported that cytochrome $c$ is released from the mitochondria during apoptosis (30-32). Thus, cytochrome $c$ constitutes a sensitive apoptotic marker of considerable importance. The mechanisms that regulate the release of cytochrome $c$ include pore formation in the outer mitochondrial membrane and opening of the permeability transition pore (33). The pore opening and rupture of the outer mitochondrial membrane cause a collapse of the mitochondrial membrane potential. The cytosolic release of cytochrome $c$ interacts with ATP, Apaf-1 and pro-caspase-9, leading to the transformation of pro-caspase- 9 to caspase- 9 , followed by the activation of caspase- 3 and initiation of a proteolytic

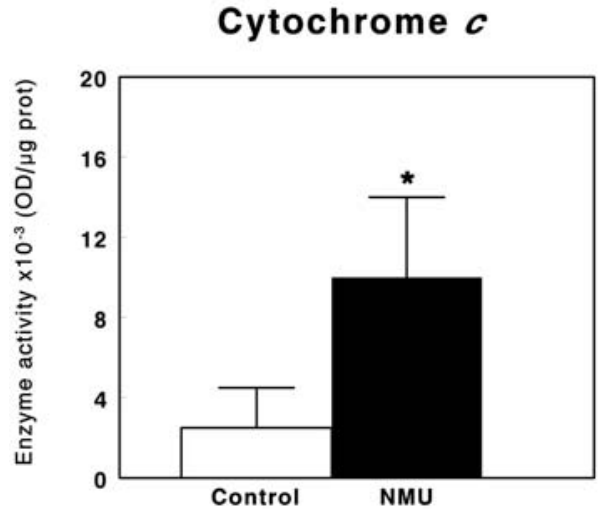

Figure 4. Analysis of cytochrome $c$ release after an NMU-induced mammary tumour. Cytochrome $c$ release was measured by using an ELISA kit following the manufacturer's recommendations. Values are expressed in an optical density $(\mathrm{OD}) / \mu \mathrm{g}$ protein $\left(\right.$ mean $\left.\pm \mathrm{SEM} ;{ }^{*} \mathrm{P}<0.05\right)$.

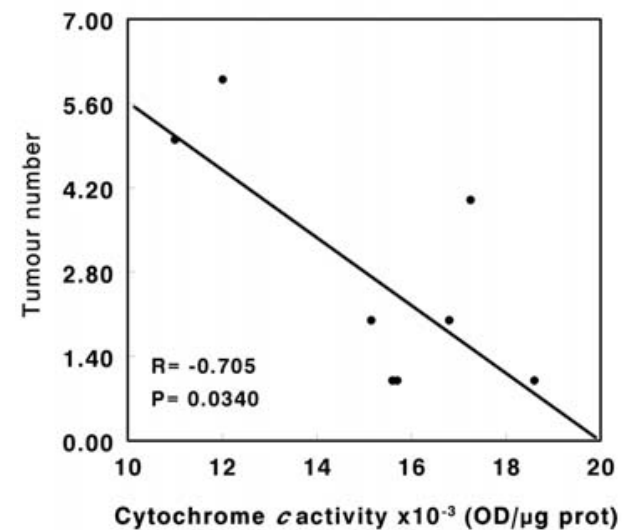

Figure 5. Simple regression found between the mean tumour number and cytochrome $c$, indicating the correlation coefficient $(\mathrm{R})$ and significance level (P).

cascade (30). In addition to its actions in preventing the release of cytochrome $c, \mathrm{Bcl}-\mathrm{xl}$ has been shown to form a ternary complex with Apaf-1 and caspase-9, possibly inhibiting the ability of Apaf-1 to activate caspase-9 (34). Therefore, it is possible that the activation of caspase- 3 appears to be an independent feature of the cytochrome $c$ release and caspase-9 activation. In contrast, the phosphorylation of caspase- 9 by a protein kinase promotes cell survival and contributes to tumorigenesis (35). Therefore, cytochrome $c$ released from mitochondria is an essential co-factor for the activation of caspase-3-like proteases. Nevertheless, several lines of evidence have suggested that the release of cytochrome $c$ occurs independently of the alteration of mitochondrial membrane permeability (36). However, the precise sequence of events occurring in the disruption of mitochondrial function followed by cytochrome $c$ release is not exactly determined in carcinogen-induced tumours. Our data also revealed a negative relationship between cytochrome $c$ release and the tumour number, indicating that despite the increase of cytochrome $c$ release from rats treated with NMU, an increase of the tumour number is related to a reduction of cytochrome $c$ production. 
We suggest that the non-activation of caspase- 9 activity constitutes a critical event for the suppression of apoptosis, due to its being responsible for the cell growth and development of tumours in this animal model. We have found no correlation between caspase- 9 activity and the number and size of tumours, whereas the release of cytochrome $c$ correlates significantly with the tumour number. Similarly, caspase- 3 and -8 activities correlate with tumour size. We hypothesize that in mammary tumours induced by NMU, suppression of the the apoptotic mitochondrial pathway occurs through a nonactivating process of caspase- 9 activity, despite the release of cytochrome $c$. Although the apoptotic death receptor-mediated pathway is activated, it is not enough to maintain the balance between proliferation and apoptosis, and thus determine the overall growth of the tumour.

\section{Acknowledgements}

This work was supported by Junta de Andalucía through PAI CVI-296 and Universidad de Jaén through the grant UJA2003/014. E.P. is a predoctoral fellow from Ministerio de Educación y Ciencia (Spain).

\section{References}

1. Gullino PM, Pettigrew HM and Grantham FH: N-nitrosomethylurea as mammary gland carcinogen in rats. J Natl Cancer Inst 54: 401-414, 1975.

2. McCormick DL, Adamowski CB, Fiks A and Moon RC: Lifetime dose-response relationships for mammary tumor induction by a single administration of N-methyl-N-nitrosourea. Cancer Res 41: 1690-1694, 1981.

3. Welsch CW: Host factors affecting the growth of carcinogeninduced rat mammary carcinomas: a review and tribute to Charles Brenton Huggins. Cancer Res 45: 3415-3443, 1985.

4. Russo J, Gusterson BA, Rogers AE, Russo IH, Wellings SR and van Zwieten MJ: Comparative study of human and rat mammary tumorigenesis. Lab Invest 62: 244-278, 1990.

5. Thompson HJ and Adlakha H: Dose-responsive induction of mammary gland carcinomas by the intraperitoneal injection of 1-methyl-1-nitrosourea. Cancer Res 51: 3411-3415, 1991.

6. Russo IH and Russo J: Hormonal approach to breast cancer prevention. J Cell Biochem 77: 1-6, 2000.

7. Goldstein SR: Drugs for the gynecologist to prescribe in the prevention of breast cancer: current status and future trends. Am J Obstet Gynecol 182: 1121-1126, 2000.

8. Russo J and Russo IH: Experimentally induced mammary tumors in rats. Breast Cancer Res Treat 39: 7-20, 1996.

9. Parkin DM, Pisani P and Ferlay J: Estimates of the worldwide incidence of 25 major cancers in 1990. Int J Cancer 80: 827-841, 1999.

10. Debatin K: Activation of apoptosis pathways by anticancer treatment. Toxicol Lett 112-113: 41-48, 2000.

11. Shao ZM, Li J, Wu J, Han QX, Shen ZZ, Fontana JA and Barsky SH: Neo-adjuvant chemotherapy for operable breast cancer induces apoptosis. Breast Cancer Res Treat 53: 263-269, 1999.

12. Hickman JA: Apoptosis induced by anticancer drugs. Cancer Metastasis Rev 11: 121-139, 1992.

13. Verheij M, van Blitterswijk WJ and Bartelink H: Radiationinduced apoptosis - the ceramide-SAPK signaling pathway and clinical aspects. Acta Oncol 37: 575-581, 1998.

14. Ellis PA, Saccani-Jotti G, Clarke R, Johnston SR, Anderson E, Howell A, A'Hern R, Salter J, Detre S, Nicholson R, et al: Induction of apoptosis by tamoxifen and ICI 182780 in primary breast cancer. Int J Cancer 72: 608-613, 1997.
15. Wu J: Apoptosis and angiogenesis: two promising tumor markers in breast cancer (Review). Anticancer Res 16: 22332239, 1996.

16. Reed JC: Dysregulation of apoptosis in cancer. J Clin Oncol 17: 2941-2953, 1999.

17. Tamm I, Schriever F and Dorken B: Apoptosis: implications of basic research for clinical oncology. Lancet Oncol 2: 33-42, 2001.

18. Chandra D, Choy G, Deng X, Bhatia B, Daniel P and Tang DG: Association of active caspase 8 with the mitochondrial membrane during apoptosis: potential roles in cleaving BAP31 and caspase 3 and mediating mitochondrion-endoplasmic reticulum cross talk in etoposide-induced cell death. Mol Cell Biol 24: 6592-6607, 2004.

19. Nicholson DW: Caspase structure, proteolytic substrates, and function during apoptotic cell death. Cell Death Differ 6: 1028-1042, 1999

20. Ashkenazi A and Dixit VM: Death receptors: signaling and modulation. Science 281: 1305-1308, 1998.

21. Muzio M, Chinnaiyan AM, Kischkel FC, O'Rourke K, Shevchenko A, Ni J, Scaffidi C, Bretz JD, Zhang M, Gentz R, et al: FLICE, a novel FADD-homologous ICE/CED-3-like protease, is recruited to the CD95 (Fas/APO-1) death-inducing signaling complex. Cell 85: 817-827, 1996.

22. Peter ME and Krammer PH: The CD95(APO-1/Fas) DISC and beyond. Cell Death Differ 10: 26-35, 2003.

23. Scaffidi C, Fulda S, Srinivasan A, Friesen C, Li F and Tomaselli KJ, Debatin KM, Krammer PH and Peter ME: Two CD95 (APO-1/ Fas) signaling pathways. EMBO J 17: 1675-1687, 1998.

24. Scaffidi C, Medema JP, Krammer PH and Peter ME: FLICE is predominantly expressed as two functionally active isoforms, caspase-8/a and caspase-8/b. J Biol Chem 272: 26953-26958, 1997.

25. Li P, Nijhawan D, Budihardjo I, Srinivasula SM, Ahmad M, Alnemri ES and Wang X: Cytochrome c and dATP-dependent formation of Apaf-1/caspase-9 complex initiates an apoptotic protease cascade. Cell 91: 479-489, 1997.

26. Rivera ES, Andrade N, Martin G, Melito G, Cricco G, Mohamad N, Davio C, Caro R and Bergoc RM: Induction of mammary tumors in rat by intraperitoneal injection of NMU: histopathology and estral cycle influence. Cancer Lett 86: 223-228, 1994.

27. Vakkala M, Paakko P and Soini Y: Expression of caspases 3, 6 and 8 is increased in parallel with apoptosis and histological aggressiveness of the breast lesion. Br J Cancer 81: 592-599, 1999.

28. Slee EA, Harte MT, Kluck RM, Wolf BB, Casiano CA, Newmeyer DD, Wang HG, Reed JC, Nicholson DW, Alnemri ES, et al: Ordering the cytochrome c-initiated caspase cascade: hierarchical activation of caspases-2, -3, -6, -7, -8, and -10 in a caspase-9-dependent manner. J Cell Biol 144: 281-292, 1999.

29. Cohen GM: Caspases: the executioners of apoptosis. Biochem J 326: 1-16, 1997.

30. Li H, Zhu H, Xu CJ and Yuan J: Cleavage of BID by caspase 8 mediates the mitochondrial damage in the Fas pathway of apoptosis. Cell 94: 491-501, 1998.

31. Li P, Nijhawan D and Wang X: Mitochondrial activation of apoptosis. Cell 116: S57-S59, 2004.

32. Zou H, Henzel WJ, Liu X, Lutschg A and Wang X: Apaf-1, a human protein homologous to C. elegans CED-4, participates in cytochrome c-dependent activation of caspase-3. Cell 90: 405-413, 1997.

33. Thompson CB: Apoptosis in the pathogenesis and treatment of disease. Science 267: 1456-1462, 1995.

34. Pan G, O'Rourke K and Dixit VM: Caspase-9, Bcl-XL, and Apaf-1 form a ternary complex. J Biol Chem 273: 5841-5845, 1998.

35. Allan LA, Morrice N, Brady S, Magee G, Pathak S and Clarke PR: Inhibition of caspase-9 through phosphorylation at Thr 125 by ERK MAPK. Nat Cell Biol 5: 647-654, 2003.

36. Bossy-Wetzel E, Newmeyer DD and Green DR: Mitochondrial cytochrome c release in apoptosis occurs upstream of DEVDspecific caspase activation and independently of mitochondrial transmembrane depolarization. EMBO J 17: 37-49, 1998. 